\title{
Familial Occurrence of Persistent Müllerian Structures in Otherwise Normal Males
}

\author{
C. G. D. BROOK, H. WAGNER, M. ZACHMANN, A. PRADER, S. ARMENDARES, S. FRENK, \\ P. ALEMÁN, S. S. NAJJAR, M. S. SLIM, N. GENTON, C. BOZIC
}

Department of Paediatrics, University of Zürich, Switzerland

C. G. D. BROOK, M.D., M.R.C.P., Research Fellow

H. WAGNER, M.D., Research Fellow

M. ZACHMANN, M.D., Physician

A. PRADER, M.D., Professor

Hospital de Pediatria, Centro Médico Nacional, México

S. ARMENDARES, M.D., Physician

S. FRENK, M.D., Professor
P. ALEMAN, M.D., Physicia

Departments of Paediatrics and Surgery, American University, Beirut, Lebanon

S. S. NAJJAR, M.D., Professor

M. S. SLIM, M.D., Surgeon

Departments of Paediatric Surgery and Pathology, University of Lausanne, Switzerland

N. GENTON, M.D., Professor

C. BOZIC, M.D., Pathologist
PAIR 1

These patients were seen in the department of paediatrics, University of Zürich. They are shown with their normal siblings in fig 1. There was no consanguinity in the parents.

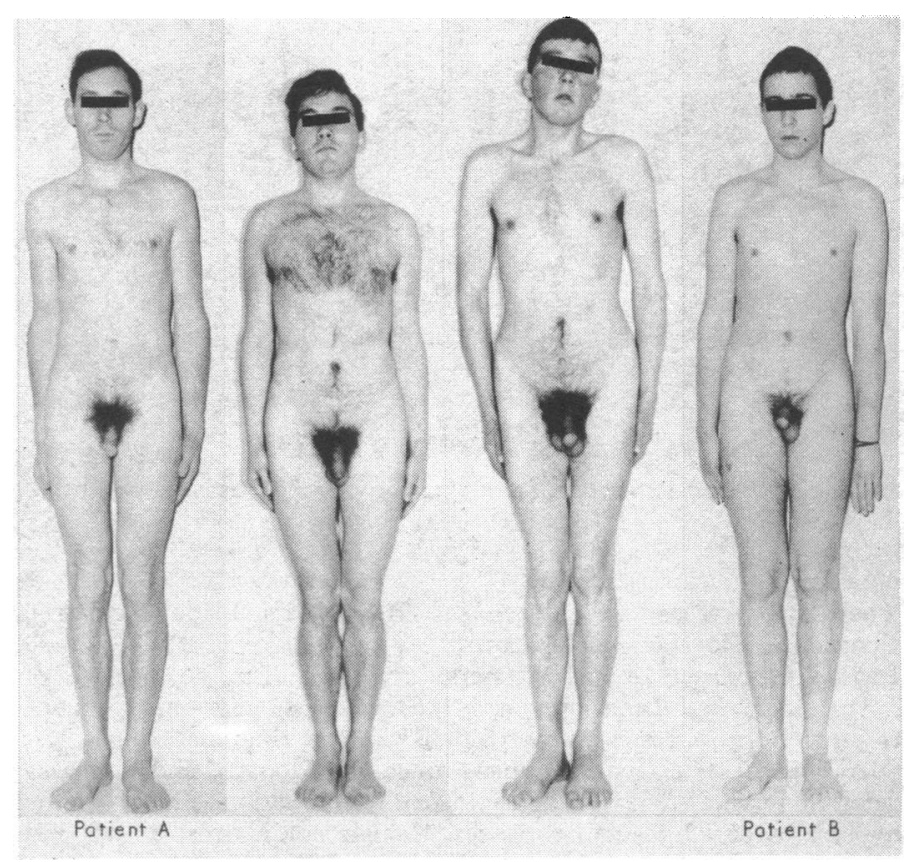

FIG. 1-Pair of siblings with persistent Müllerian structures. with their normal brothers.

Patient A was noted to have bilateral cryptorchidism at birth At the age of 19 years a right inguinal hernia was repaired and a uterus, Fallopian tubes, and two gonads were found in the sac. One year later at laparotomy for an acute abdomen the previous findings of persistent Müllerian structures were confirmed. Macroscopically the right testis was normal but the left gonad was replaced by a tumour. This was removed and found to be a seminoma. At the time of writing the patient was well and married though infertile.

Patient B presented with a left inguinal hernia at the age of 16 years. He had been noted to have cryptorchidism on the right and minimal glandular hypospadias at birth. At the age of 19 years the hernia was repaired and in the sac were found a uterus,

Details of Eight Cases in Four Sibships of Males with Persistent Müllerian Structures

\begin{tabular}{|c|c|c|c|c|c|c|}
\hline & Patient & $\begin{array}{c}\text { Age } \\
\text { (Years) }\end{array}$ & Presenting Symptom & External Genitalia & Internal Genitalia & Chromosomes \\
\hline \multirow{3}{*}{ Pair 1, Zürich } & A & 30 & Right inguinal hernia & $\begin{array}{l}\text { Bilateral cryptorchid, } \\
\text { normal penis }\end{array}$ & $\begin{array}{l}\text { Testis, seminoma, uterus, } \\
2 \text { Fallopian tubes }\end{array}$ & Chromatin-negative \\
\hline & B & 20 & Left inguinal hernia & $\begin{array}{l}\text { Right crytorchid, } \\
\text { glandular hypospadias }\end{array}$ & $\begin{array}{l}\text { Hypoplastic testis, uterus, } \\
\text { 2 Fallopian tubes }\end{array}$ & $46 \mathrm{XY}$ \\
\hline & C & 5 & Bilateral cryptorchidism & Bilateral cryptorchid, & Hypoplastic testes, uterus, & $46 \mathbf{X Y}$ \\
\hline \multirow[t]{2}{*}{ Pair 2, Mexico } & D & 4 & Bilateral cryptorchidism & $\begin{array}{l}\text { Bormal penis } \\
\text { Bilateral cryptorchid, } \\
\text { normal penis }\end{array}$ & $\begin{array}{l}\text { Hypoplaptic testess uterus, } \\
\text { 2 Fallopian tubes }\end{array}$ & $46 \mathrm{XY}$ \\
\hline & E & 8 & Left inguinal hernia & Right Cryptorchid, & Testis, uterus, & $46 \mathrm{XY}$ \\
\hline \multirow[t]{2}{*}{ Pair 3, Beirut } & $\mathbf{F}$ & 4 & Right inguinal hernia & $\begin{array}{l}\text { normal penis } \\
\text { Left cryptorchid, }\end{array}$ & $\begin{array}{l}22 \text { Fallopian tubes } \\
\text { Testis, uterus, }\end{array}$ & $46 \mathrm{XY}$ \\
\hline & G & 9 & Bilateral cryptorchidism & $\begin{array}{l}\text { normal penis } \\
\text { Bilateral cryptorchid, }\end{array}$ & $\begin{array}{l}2 \text { Fallopian tubes } \\
\text { Hypoplastic testes, }\end{array}$ & $46 \mathrm{XY}$ \\
\hline Pair 4, Lausanne & $\mathbf{H}$ & 12 & Bilateral cryptorchidism & $\begin{array}{l}\text { normal penis } \\
\text { Bilateral cryptorchid, } \\
\text { normal penis }\end{array}$ & $\begin{array}{l}\text { uterus } \\
\text { Hypoplastic testes, uterus, } \\
\text { 2 Fallopian tubes }\end{array}$ & $46 X Y$ \\
\hline
\end{tabular}


two Fallopian tubes, and two gonads. Both of these showed histological changes characteristic of cryptorchid testes, even though the left was descended; there was tubular hypoplasia and atrophy and absence of the germinal epithelium with proliferation of the Leydig cells. In one part of the right gonad there was atypical germinal cell proliferation, a change sometimes seen around a seminoma and which could perhaps be interpreted as changes of a seminoma in situ (fig. 2). The left testis was left in situ in the scrotum and the remaining structures were replaced in the abdomen. The patient remained well but had azoospermia.

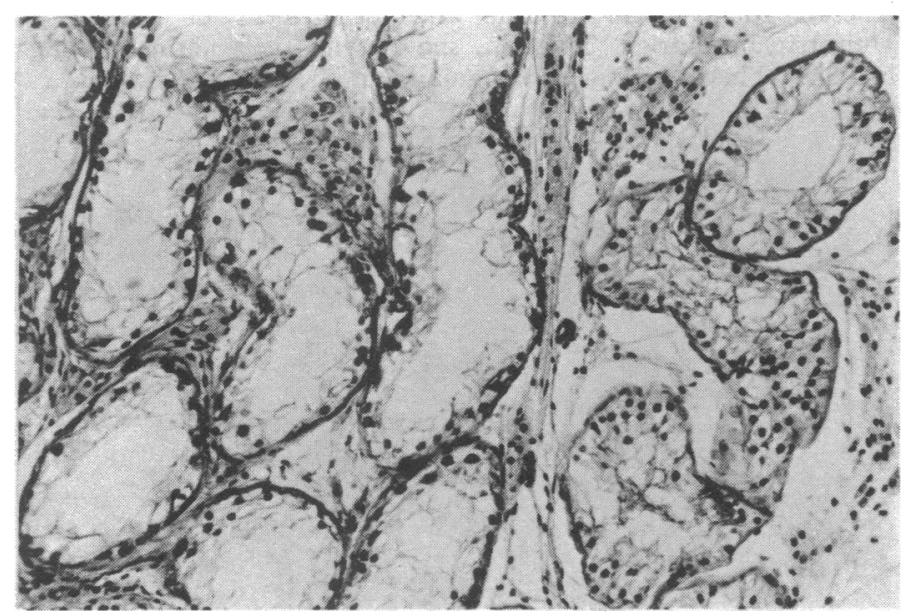

PIG. 2-Histological specimen from right cryptorchid testis of patient $B$. (x 120.)

PAIR 2

These two cases were seen at the Hospital de Pediatria, Centro Médico Nacional, Mexico.

Patient C presented with bilateral cryptorchidism at the age of 5 years. He had been previously treated with chorionic gonadotrophin but no testes were palpable in the inguinal canals. At operation a uterus, two Fallopian tubes, two gonads, and two vasa deferentia were removed. Histological examination showed some hypoplasia of all testicular tissues, though epididymis, a vas, and normal tunica albuginea were identified. These findings are not definitely abnormal but there was a diminution in the number of spermatogonia similar to that found in cryptorchid testes. The age of the patient made interpretation of the findings difficult.

Patient D presented with his brother at the age of 4 years also with bilateral cryptorchidism. The operative and histological findings were identical.

PAIR 3

These patients were seen in the department of paeditrics, American University of Beirut.

Patient $E$ presented at the age of 8 years with a left inguinal hernia and a right undescended testis and hypoplastic scrotum on that side. At the age of 4 years he had received chorionic gonadotrophin without effect except for enlargement of the penis. The left gonad was normal and freely mobile. At operation the right inguinal canal was seen to be empty but the left hernial sac contained a uterus and two Fallopian tubes. The left gonad presented a "cystic" appearance; its epididymis and vas were not clearly identifiable. The uterus was attached on the right side to a similar looking intra-abdominal gonad. All the structures were removed. Histological examination of the gonads showed testicular tissue, and, in addition, fetal epididymis and vas deferens were found attached to each.

Patient $F$ presented at the age of 4 years at the same time as his brother because of a right inguinal hernia and left cryptorchidism. He had had no treatment previously and his penis was normal. The operative and histological findings were identical with those of his brother except that the uterus was in the hernial sac on the right.

PAIR 4

Both of these patients were seen at the Hopital Cantonal Universitaire, Lausanne.

Patient $G$ was the oldest of three children, the second of whom appeared entirely normal. He presented at the age of 9 years with bilaterally undescended testes but with no other abnormal physical signs. At operation bilateral intra-abdominal gonads were found which were shown histologically to be hypoplastic testes. A hypoplastic uterus was felt in the retroperitoneal space. The testes were placed in the scrotum and subsequent development of secondary sex characteristics was normal.

Patient $\mathrm{H}$ was first seen at the age of 6 years with his oldest brother. He, too, appeared normal except for bilateral cryptorchidism, but for social reasons operation was not performed at that time. It was not until seven years later that he was seen again, by which time he was in early puberty. An exploratory laparotomy showed a uterus, Fallopian tubes, and two gonads which proved to be hypoplastic testes.

\section{Discussion}

The interest of the familial occurrence of persistent Müllerian structures in chromosomally normal males with testes lies in the implications it has for the physiology of sexual differentiation in the fetus. Jost (1947) showed that female organogenesis follows a straight developmental line; the presence of a $Y$ chromosome confers maleness through the differentiation of a testis on a system which would otherwise become female. In order to achieve masculinization the fetal testis inhibits the Müllerian ducts, stimulates the Wolffian ducts, and masculinizes the other parts of the reproducrive tract. Testosterone has the same masculinizing effect but does not inhibit the Müllerian system. The fetal testis, it seems, elaborates both a masculinizing hormone, which may be testosterone, and a Müllerian-inhibiting substance. Experiments with an androgen antagonist, cyproterone acetate, have confirmed this by showing prevention of masculinization without prevention of the suppression of Müllerian structures (Elger, 1966).

Josso (1972a) showed that the Müllerian-inhibiting substance is produced by the fetal testis at an early stage of gestation but not by postnatal testes. The substance, which is probably produced by the Sertoli cells of the seminiferous tubules (Josso, 1973), is likely to have a molecular weight of over 15,000 and cannot therefore be a steroid (Josso, 1972b). A fetal protein seems more likely, which would be consistent with the finding that the inhibiting substance is no longer present in postnatal testes, since it is known that many fetal proteins are not elaborated after birth.

The production of two substances by the fetal testis explains many of the problems of intersex. Inadequate androgen secretion at the time of organogenesis accounts for the genital ambiguities of patients with defects in testosterone biosynthesis. In testicular feminization there is peripheral androgen insensitivity, so that although testosterone levels reach the normal range for males (French et al., 1966) these patients have female genitalia with complete suppression of Müllerian structures. In cases of males with persistent Müllerian structures the male external genitalia are well developed and androgen secretion must therefore be normal both in the fetal period and later, as the masculine habitus of pair 1 and the normal puberty of pair 4 in the present report indicate. Patient $B$ did have minimal glandular hypospadias, but as this is such a common malformation (Petersson, 1964) and is not usually found in this syndrome we do not feel that its presence in this case was more than coincidental.

The present findings are explicable, therefore, only on the basis of a failure of the fetal testis to produce the Müllerianinhibiting substance or failure of the tissues to respond to it or, as timing in these events appears to be critical (Jost, 1972), the elaboration of the substance when the tissues are no longer able to respond to it. Which of these possibilities is correct must await identification of the substance and its experimental use.

The familial incidence raises the question of the mode of inheritance. In one report (Güell-González et al., 1970) a maternal cousin had bilateral cryptorchidism and may also have had this condition, but as the exact relationship to the probands was not described it is not possible to speculate 
further. Since there were apparently normal male siblings in the families of pairs 1 and 4, and in others reponted in the literature, the condition must be inherited either as an autosomal recessive or as a sex-linked recessive character. Elucidation of the exact mode of inheritance requires a search for the abnormality in succeeding generations. Though patients with this condition have been reported to be fertile (Nilson, 1939; Young, 1951) proof of paternity in these cases has been lacking. The one report of a spermogram (Giacobine, 1946) showed a reduced total count with few motile sperms and $35 \%$ atypical forms: both patients in pair 1 had azoospermia. Since one report in the literature concerns the improbable case of a man with bilateral cryptorchidism having eight children (Keiffer, 1909) the evidence for fertility as a whole seems somewhat questionable.

In view of the high incidence of cryptorchidism in this condition, and the finding in patients $B, E$, and $F$ that the descended testis was also hypoplastic, a lack of fertility would not be surprising, but more fundamental questions about cryptorchid testis are raised by this. It is not known why the normal testis descends nor whether cryptorchid testes are primarily or secondarily hypoplastic (Salle et al., 1968); the present cases favour the former, since the descended testes were abnormal. A possible explanation for the syndrome could be that though androgens are produced normally by the interstitial cells Müllerian-inhibiting substance is not produced by the hypoplastic seminiferous tubules. If this were correct, however, persistent Müllerian structures would occur more frequently in cryptorchid subjects whose testes are not histologically different from those of the present patients. An inherited error in the production of or response to Müllerianinhibiting substance is therefore more likely.

It is well known that malformed structures have a greater than normal incidence of malignancy, which explains the increased incidence of neoplasia in cryptorchid testes whether or not they are surgically placed in the scrotum (Robinson and Engle, 1954). Presumably this is the reason for the seemingly high incidence of malignancy in men with persistent Müllerian structures reported in the literature-seminoma (Boulvin, 1964, and patient A), choriocarcinoma (Taub, 1954), embryonal carcinoma (Metcalfe, 1930), and teratoma (Dvorak, 1924; d'Arcy McCrea, 1930). There is, however, no good evidence that the cryptorchid testes of these patients are more susceptible to malignant change than the testes of "normal" oryptorchid subjects, and we do not agree with Jirasek (1971) that there is more indication than is usual in cryptorchid subjects to remove the testes of these individuals.

We are grateful to Professor Hedinger (Zürich) for his advice on testicular histology and to Dr. Nathalie Josso (Paris) for her helpful criticism of the manuscript. C.G.D.B. gratefully acknowledges the financial support of the Wellcome Trust.

\section{References}

Boulvin, R. (1964). Annales de Chirurgie, 18, 1340.

d'Arcy McCrea, E. (1930). British fournal of Surgery, 18, 91

David, L., Saez, J. M., and Francois, R. (1972). Acta Paediatrica Scandinavica, 61, 249 .

Dvorak, R. (1924). Virchows Archiv für pathologische Anatomie und Physiologie, 251, 616.

Elger, W. (1966). Archives d'Anatomie Microscopique et de Morphologie

French, F. S., et al. (1966). Fournal of Clinical Endocrinology and Metabolism, 26, 493 .

Giacobine, J. W. (1946). American fournal of Surgery, 72, 604.

Güell-González, J. R., Paramio-Ruibal, A., and Delgado-Morales, B. (1970) Revue Roumaine d'Endocrinologie, 7, 343 .

Jirasek, J. E. (1971). In Development of the Genital System and Male Pseudohermaphroditism, ed. M. M. Cohen, p. 88. The Johns Hopkins Press, Baltimore.

Josso, N. (1972a). Biology of the Neonate, 20, 368

Josso, N. (1972b). Fournal of Clinical Endocrinology and Metabolism, 34, 265. Josso, N. (1973). Acta Paediatrica Scandinavica, 62, 89.

Jost, A. (1947). Archives d'Anatomie Microscopique et de Morphologie Expérimentale, 36, 271.

Jost, A. (1972). In Mammalian Reproduction, ed. H. Gibian and E. J. Plotzt, p. 4. Heidelberg, Springer.

Keiffer (1909). Gynécologie, 13, 138.

Metcalfe, R. H. (1930). British Yournal of Surgery, 18, 335.

Nilson, O. (1939). Acta Chirurgica Scandinavica, 83, 231.

Petersson, F. (1964). Lancet, 1, 675.

Robinson, J. N., and Engle, E. T. (1954). Fournal of Urology, 71, 726.

Royer, P., Pellerin, D., Habib, R., Vermeil, G., and Rodriguez-Soriano, J. (196i). Annales de Pédiatrie, 37, 143.

Salle, B., Hedinger, C., and Nicole, R. (1968). Acta Endocrinologica, 58, 67. Taule, B., Hedinger, C., and Nicole, R. (1968).

Young, D. (1951). Fournal of Obstetrics and Gynaecology of the British Empire, 58, 830 .

\title{
Insulinopenic Diabetes in Africa
}

\author{
A. C. B. WICKS, J. J. JONES
}

British Medical fournal, 1973, 1, 773-776

\section{Summary}

The high proportion of unrefined carbohydrates (maize meal) in the diet of Africans could be responsible for their low insulin secretion. The consequent insulinopenia in the general African population may explain the comparative rarity of typical non-insulin dependent diabetes mellitus, and also the virtual absence of coronary heart disease. Changes in growth hormone secretion and in serum lipids, known to be associated with diabetes in Europeans, are also found in African patients.

\footnotetext{
The Godfrey Huggins School of Medicine, University of Rhodesia,
Salisbury

A. C. B. WICKS, M.B., M.R.C.P., Lecturer in Medicine

J. J. JONES, PH.D., M.R.c.s., Professor of Preclinical Studies
}

\section{Introduction}

Diabetes mellitus was thought to be a rare disease in the indigenous populations of Africa (Tulloch, 1966), and coronary thrombosis as a complication is virtually unknown (Jackson et al., 1966; Seftel and Walker, 1966). In this paper an attempt is made to determine how far the characteristic features of diabetes in Africans can be related to diet and to insulin and growth hormone secretion.

\section{Patients and Methods}

In 1971, 107 newly diagnosed diabetic patients were admitted to Harare Hospital for stabilization. Of these, 20 were already receiving insulin and, of the remaining 87, 76 were selected at random for serum insulin assay before starting treatment. After an overnight fast, venous blood was collected for insulin assay (Hales and Randle, 1963) from 42 of these patients during a 50-g oral glucose tolerance test.

The results for insulin secretion during the glucose tolerance test from the healthy contrast group of 50 urban male 